\title{
Major Salivary Gland Sarcoma
}

National Cancer Institute

\section{Source}

National Cancer Institute. Major Salivary Gland Sarcoma. NCI Thesaurus. Code C5983.

A rare malignant soft tissue neoplasm that arises from the parotid gland, submandibular gland, or sublingual gland. Representative examples include fibrosarcoma, angiosarcoma, leiomyosarcoma, and Kaposi sarcoma. 